\title{
Atmosfera controlada associada ao 1-metilciclopropeno na preservação da qualidade de kiwi 'tewi'
}

\author{
Controlled atmosphere associated with 1-methylcyclopropene in the preservation of \\ 'Tewi' kiwifruit quality
}

\author{
Camila Pegoraro ${ }^{1,2}$, Tatiane Timm Storch ${ }^{1,2}$, Giseli Rodrigues Crizel ${ }^{1,2}$, Wanderson Araujo Ferreira' ${ }^{1}$, César Luis Girardi ${ }^{1 *}$ \\ 1 Embrapa Uva e Vinho, Bento Gonçalves/RS - Brasil \\ 2 Universidade Federal de Pelotas (UFPel), Faculdade de Agronomia Eliseu Maciel, Departamento de Ciência e Tecnologia de Alimentos, Campus \\ Capão do Leão, Pelotas/RS - Brasil
}

\section{*Corresponding Author}

César Luis Girardi, Embrapa Uva e Vinho, Rua Livramento, 515, CEP: 95700-000, Bento Gonçalves/RS - Brasil, e-mail: cesar.girardi@embrapa.br

Cite as: Controlled atmosphere associated with 1-methylcyclopropene in the preservation of 'Tewi' kiwifruit quality. Braz. J. Food Technol. v. 19, e2014078, 2016.

Received: Dec. 22, 2014; Accepted: Jan. 22, 2016

\section{Resumo}

O objetivo deste trabalho foi determinar os efeitos de diferentes tecnologias de armazenamento na qualidade físico-química de kiwis da cultivar Tewi. Após a colheita, parte dos frutos foi submetida ao tratamento com 1-metilciclopropeno (1-MCP) e, posteriormente, frutos tratados e não tratados foram submetidos a diferentes condições de armazenamento, conforme segue: armazenamento em temperatura ambiente $\left(20^{\circ} \mathrm{C} \pm 0,5^{\circ} \mathrm{C}\right)$ durante 12 dias; armazenamento refrigerado $\left(0^{\circ} \mathrm{C} \pm 0,5^{\circ} \mathrm{C}\right) \mathrm{com}$ ou sem controle da atmosfera $\left(3 \mathrm{KPa} \mathrm{O} \mathrm{O}_{2}\right.$ e $\left.5 \mathrm{KPa} \mathrm{CO}_{2}\right)$, e com ou sem absorção de etileno durante dois e quatro meses. Foram avaliadas a firmeza de polpa, o teor de sólidos solúveis e a acidez titulável. Verificou-se que, independentemente da tecnologia de conservação, houve uma diminuição na firmeza de polpa já aos dois meses de armazenamento, sendo a condição atmosfera controlada associada ao uso do 1-MCP a mais eficaz na retenção desse atributo. Frutos mantidos em temperatura ambiente apresentaram relação direta entre a redução da firmeza de polpa e o aumento do índice de sólidos solúveis; no entanto, após o armazenamento, essa relação nem sempre ocorreu. A maior acidez titulável foi verificada em frutos que receberam 1-MCP. Kiwis 'Tewi' apresentam bom potencial de conservação, podendo permanecer armazenados por até quatro meses em atmosfera controlada associada ao controle do etileno pelo uso de 1-MCP ou por absorção do etileno.

Palavras-chave: Actinidia deliciosa; Qualidade físico-química; Pós-colheita; Firmeza de polpa.

\section{Summary}

The aim of this study was to evaluate the effect of different storage technologies on the physical and chemical qualities of 'Tewi' kiwifruits. After harvesting, part of the fruits was treated with 1-methylcyclopropene (1-MCP), and then both the treated and non-treated fruits were stored under different conditions, as follows: storage at room temperature $\left(20^{\circ} \mathrm{C} \pm 0.5^{\circ} \mathrm{C}\right)$ for twelve days; refrigerated storage $\left(0^{\circ} \mathrm{C} \pm 0.5^{\circ} \mathrm{C}\right)$, with or without a controlled atmosphere $\left(3 \% \mathrm{O}_{2}\right.$ and $\left.5 \% \mathrm{CO}_{2}\right)$; and storage with or without ethylene adsorption for two and four months. The firmness of the flesh, soluble solids content and titratable acidity were evaluated during storage. It was noted that regardless of storage technology there was a reduction in firmness after two months. The controlled atmosphere conditions with 1-MCP were the most effective in retaining firmness. Fruits kept at room temperature showed a direct relationship between the reduction in flesh firmness and the increase in soluble solids content, although this relationship was not always observed after storage. The highest titratable acidity was observed in the fruits treated with 1-MCP. 'Tewi' kiwis showed good conservation potential, and could be stored for up to four months in a controlled atmosphere with ethylene management using 1-MCP or ethylene absorption.

Keywords: Actinidia deliciosa; Physicochemical quality; Postharvest; Flesh firmness. 


\section{Introdução}

A cultura do kiwi (Actinidia deliciosa) foi introduzida no Brasil na década de 1970 e, desde então, vem ganhando destaque no cenário nacional. Em função das condições climáticas, o Rio Grande do Sul caracteriza-se por ser o principal produtor de kiwis do Brasil (VIEIRA et al., 2010), sendo responsável pela metade da quantidade do fruto produzido no país. Embora tenha sido observado um aumento constante na produção do fruto, verifica-se que a maior parte do kiwi consumido é proveniente de importações (SILVEIRA et al., 2012). Esse cenário evidencia claramente uma oportunidade de expansão da cultura, ao mesmo tempo em que constitui um desafio, considerando-se a deficiência de tecnologias de manejo durante a produção e após a colheita dos frutos. Essa situação se agrava ainda mais nas cultivares menos produzidas, como é o caso da Tewi, que, apesar da pouca expressão, apresenta baixo requerimento de frio durante o cultivo, sendo uma opção interessante para regiões com menor ocorrência de baixas temperaturas.

A cultivar Tewi é originária das Ilhas Canárias e foi selecionada por possuir baixa necessidade de frio hibernal (aproximadamente 100 horas) e pela alta produtividade, proveniente esta dos elevados índices de brotação e fertilidade. No entanto, kiwis 'Tewi' são pouco cultivados, pois apresentam frutos de tamanho pequeno e baixo potencial de conservação em armazenamento refrigerado (FERGUSON, 1999).

Kiwis podem ser conservados a $0{ }^{\circ} \mathrm{C}$ por um período de três a quatro meses; no entanto, a firmeza de polpa é reduzida rapidamente após o armazenamento (ZOLFAGHARI et al., 2010) e em determinadas condições, essa redução ocorre ainda dentro do ambiente de conservação (NEVES et al., 2003; YANG et al., 2013). Esse comportamento ocorre em função de o kiwi ser um fruto climatérico, altamente sensível ao etileno (HU et al., 2011), sendo suficiente uma quantidade tão baixa quanto 30 ppb desse fito-hormônio para indução do processo de amadurecimento, com drástica redução na firmeza de polpa (BRACKMANN et al., 2012).

Para estender o período de conservação de kiwis, pode-se adotar o armazenamento em atmosfera controlada ( $A C)$, bem como o controle da produção de etileno e a aplicação de inibidores da ação desse fito-hormônio, como o 1-metilciclopropeno (1-MCP) (WATKINS, 2006; BRACKMANN et al., 2012). A utilização de atmosfera controlada tem se apresentado como uma tecnologia bastante promissora na conservação de kiwis (VIEIRA et al., 2010); porém, para que o armazenamento em AC seja eficiente, os frutos não devem estar em ambiente que contenha etileno, sendo indicada a remoção desse fito-hormônio durante o período de conservação (KOUKOUNARAS; SFAKIOTAKIS, 2007).
O 1-MCP é um potente inibidor da ação do etileno (BLANKENSHIP; DOLE, 2003; LALLU; BURDON, 2007) e tem sido utilizado de forma eficaz no controle do amadurecimento e da senescência de frutos, como maçã, banana, manga, pera, tomate e kiwi (PIRIYAVINIT et al., 2011). Desde 2002, o 1-MCP vem sendo utilizado em kiwi, resultando em atraso e diminuição da produção de etileno, e decréscimo na taxa respiratória, retardando a mudança da coloração da polpa e o amolecimento (ILINA et al., 2010). No entanto, o 1-MCP pode afetar diretamente o amadurecimento, especialmente durante a comercialização, podendo gerar um impacto negativo na aceitabilidade geral por parte do consumidor, uma vez que os frutos podem permanecer duros, não alcançando a firmeza de polpa desejada para consumo, além de não desenvolver o aroma característico do fruto maduro (WATKINS, 2006).

Considerando-se que as condições de atmosfera e a resposta ao etileno variam de acordo com a cultivar, é necessário estabelecer as concentrações de gases e o manejo do etileno de acordo com a cultivar que está sendo trabalhada. Nesse sentido, como a maioria dos estudos pós-colheita em kiwi foi conduzida para as cultivares mais produzidas no mundo - Abbot, Allison, Bruno, Monty e Hayward (ARPAIA, 1987; BRACKMANN et al., 1995; NEVES et al., 2003; ALVES et al., 2010; BLUM; AYUB, 2009; VIEIRA et al., 2010; BRACKMANN et al., 2012) -, este estudo teve como objetivo avaliar o efeito de diferentes tecnologias de armazenamento na qualidade e no período de conservação de kiwis da cultivar Tewi produzidos em condições edafoclimáticas da Serra Gaúcha.

\section{Material e métodos}

Kiwis (Actinidia deliciosa) da cultivar Tewi foram colhidos em pomar comercial, localizado no município de Farroupilha-RS, no mês de maio de 2014, com teor de sólidos solúveis entre 8 e 9 'Brix. Após a colheita, parte dos frutos foi submetida ao tratamento com $1 \mathrm{ppm}$ $\left(1 \mu \mathrm{L} \mathrm{L}^{-1}\right)$ de 1-metilciclopropeno (1-MCP) durante 24 horas, através da utilização do produto SmartFresh ${ }^{\text {TM }}$ (Agro Fresh, Rohm and Haas, PA, USA), contendo 0,14\% (fórmula para pesquisa) do princípio ativo. Para a aplicação de 1-MCP, utilizaram-se caixas hermeticamente fechadas com capacidade de $370 \mathrm{~L}$, contendo $50 \mathrm{~kg}$ de frutos. Em seguida, frutos tratados e não tratados com 1-MCP foram acondicionados em caixas plásticas de polietileno de alta densidade e armazenados em diferentes sistemas de conservação.

Visando avaliar a evolução do amadurecimento, frutos que não foram tratados com 1-MCP, denominados controle, foram mantidos a $\pm 20{ }^{\circ} \mathrm{C}$ com $75-80 \%$ de umidade relativa (temperatura ambiente - TA) durante 12 dias, com avaliações realizadas no momento da 
Atmosfera controlada associada ao 1-metilciclopropeno na preservação da qualidade de kiwi 'tewi'

Pegoraro, C. et al.

colheita (zero dia de armazenamento) e aos seis e 12 dias após a colheita. Posteriormente, para avaliar o efeito do armazenamento refrigerado, frutos tratados e não tratados foram submetidos ao armazenamento refrigerado (AR) $\left(0^{\circ} \mathrm{C} \pm 0,5,90 \%\right.$ UR \pm 5$)$ e em atmosfera controlada (AC) ( $3 \mathrm{KPa}$ de $\mathrm{O}_{2}$ e $5 \mathrm{KPa}$ de $\mathrm{CO}_{2}$, com as mesmas condições de temperatura e umidade utilizadas em AR). Além disso, frutos não tratados foram submetidos ao armazenamento em AC com absorção de etileno (passagem do ar da atmosfera da câmara por filtro de permanganato de potássio). Os frutos permaneceram nessas condições durante dois e quatro meses, com avaliações realizadas no momento da saída da câmara (zero dia), e aos seis e 12 dias em TA, para simulação de vida útil e/ou período de comercialização. O experimento foi conduzido em blocos inteiramente casualizados, com três repetições por tratamento, com cinco frutos em cada repetição.

Neste estudo, avaliaram-se a firmeza de polpa (FP), o conteúdo de sólidos solúveis (SS) e a acidez titulável (AT). A firmeza de polpa foi medida utilizando-se penetrômetro automático (Fruit Texture Analyser), com ponteira cilíndrica de $8 \mathrm{~mm}$. As medidas foram feitas na região mediana de cada face dos frutos, após a retirada da epiderme, sendo os resultados expressos em Newton (N). O conteúdo de sólidos solúveis foi determinado no suco dos frutos, utilizando-se refratômetro digital (PR 101 Atago) com compensação automática da temperatura, com os resultados expressos em ${ }^{\circ}$ Brix. A determinação da acidez titulável foi realizada por meio da titulação de $10 \mathrm{~mL}$ de suco diluídos em $90 \mathrm{~mL}$

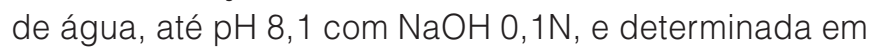
porcentagem de ácido cítrico.

Os dados obtidos foram analisados quanto à normalidade pelo teste de Shapiro Wilk, à homocedasticidade, pelo teste de Hartley, e à independência dos resíduos, que foi verificada graficamente. Posteriormente, os dados foram submetidos à análise de variância através do teste $F(p \leq 0,05)$. Constatando-se significância estatística, os efeitos das tecnologias de armazenamento e do tempo foram avaliados pelo teste de Tukey $(p \leq 0,05)$, do período de armazenamento, pelo teste $t(p \leq 0,05)$, e a comparação com o controle (temperatura ambiente-TA) foi realizada pelo teste de Dunnett $(p \leq 0,05)$ (SAS INSTITUTE, 2002).

\section{Resultados e discussão}

A firmeza de polpa, o teor de sólidos solúveis e a acidez titulável são parâmetros indispensáveis para o monitoramento do amadurecimento e da qualidade, durante o armazenamento de kiwis (BRACKMANN et al., 1995). Neste estudo, esses atributos foram avaliados em frutos de kiwi 'Tewi', submetidos a diferentes tecnologias e períodos de armazenamento.

A firmeza de polpa (FP) variou significativamente entre as condições testadas e ao longo do período de armazenamento. Verificou-se que, independentemente da tecnologia de conservação, houve uma diminuição na FP já aos dois meses de armazenamento, sendo a condição AC associada ao uso do 1-MCP (AC 1-MCP) a mais eficaz na retenção da FP, mesmo apresentando uma redução de aproximadamente $40 \%$ quando comparada à FP no momento da colheita. No momento da saída da câmara refrigerada, frutos mantidos em AC com absorção do etileno (AC com absorção de $\mathrm{C}_{2} \mathrm{H}_{4}$ ) apresentaram FP similar à de frutos armazenados em AC 1-MCP; no entanto, após seis e 12 dias em TA, frutos provenientes do armazenamento em AC com absorção de $\mathrm{C}_{2} \mathrm{H}_{4}$ apresentaram menor FP, sendo esse comportamento observado tanto aos dois quanto aos quatro meses de conservação (Tabela 1). Em kiwis da

Tabela 1. Firmeza de polpa de kiwis da cultivar Tewi, tratados e não tratados com 1-MCP, mantidos em diferentes condições de armazenamento, durante zero, 2 e 4 meses. As avaliações foram realizadas no momento da saída da câmara fria (zero dia) e após 6 e 12 dias em temperatura ambiente.

\begin{tabular}{|c|c|c|c|c|c|c|}
\hline \multicolumn{7}{|c|}{ Firmeza de polpa (Newton) } \\
\hline \multirow{2}{*}{ TA } & \multicolumn{2}{|c|}{0 dia } & \multicolumn{2}{|c|}{6 dias } & \multicolumn{2}{|c|}{12 dias } \\
\hline & \multicolumn{2}{|c|}{57,89} & \multicolumn{2}{|c|}{24,20} & \multicolumn{2}{|c|}{17,17} \\
\hline \multirow{2}{*}{ Armazenamento } & \multicolumn{3}{|c|}{2 meses } & \multicolumn{3}{|c|}{4 meses } \\
\hline & O dia & 6 dias & 12 dias & $0 \mathrm{dia}$ & 6 dias & 12 dias \\
\hline AR & $6,27 \mathrm{cA}^{1 / \star} \alpha$ & $3,64 \mathrm{cB}^{\star} \alpha$ & $2,80 \mathrm{cB} \alpha$ & $2,49 \mathrm{dA} \alpha$ & $1,37 \mathrm{~dB} \alpha$ & nd \\
\hline AR MCP & $16,10 \mathrm{bA}^{*} \alpha$ & $8,90 \mathrm{bB}^{*} \alpha$ & $5,91 \mathrm{aC}^{\star} \alpha$ & $5,78 \mathrm{cA \alpha}$ & $4,40 \mathrm{cB} \alpha$ & $3,07 \mathrm{bC} \alpha$ \\
\hline$A C$ & $21,31 \mathrm{bA}^{*} \alpha$ & $7,12 b B^{*} \alpha$ & $3,02 \mathrm{bcC}^{\star} \alpha$ & $6,71 \mathrm{cA} \alpha$ & $5,11 \mathrm{cB} \alpha$ & $3,69 a b C \alpha$ \\
\hline AC MCP & $33,90 \mathrm{aA}^{*} \alpha$ & $15,39 \mathrm{aB}^{\star} \alpha$ & $5,96 \mathrm{aC}^{*} \alpha$ & $15,30 \mathrm{bA} \alpha$ & $9,25 \mathrm{aB} \alpha$ & $4,09 \mathrm{aC} \alpha$ \\
\hline $\mathrm{AC}$ com absorção de $\mathrm{C}_{2} \mathrm{H}_{4}$ & $32,44 \mathrm{aA}^{\star} \alpha$ & $6,98 \mathrm{bB}^{\text {ns }} \alpha$ & $4,09 \mathrm{bB} * \alpha$ & 20,47 aA $\alpha$ & $6,49 \mathrm{bB} \alpha$ & $3,15 \mathrm{bC} \alpha$ \\
\hline
\end{tabular}

1": Médias acompanhadas por mesma letra minúscula na coluna não diferem entre si pelo teste de Tukey ( $p \leq 0,05)$, comparando-se as condições de armazenamentos dentro de cada dia para cada período de conservação. Médias acompanhadas por mesma letra maiúscula na linha não diferem entre si pelo teste de Tukey $(p \leq 0,05)$, comparando-se os dias dentro de cada condição de armazenamento para cada período de

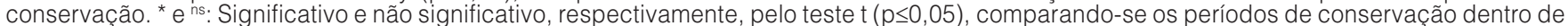
cada condição de armazenamento para cada dia. $\alpha$ e $\beta$ : Significativo e não significativo, respectivamente, em relação à testemunha (temperatura ambiente-TA) pelo teste de Dunnett $(p \leq 0,05)$. nd: Não foi possível detectar. 
cultivar Bruno, Vieira et al. (2010) também verificaram que frutos tratados com 1-MCP e mantidos em AC foram os que apresentaram maior retenção da firmeza de polpa. A menor perda de FP observada nos frutos mantidos em AC 1-MCP pode ser explicada pela inibição da ação do etileno, devido à ligação do 1-MCP nos receptores do hormônio na membrana, resultando no atraso do processo de amadurecimento do fruto, como a redução da firmeza de polpa (KOUKOUNARAS; SFAKIOTAKIS, 2007). No entanto, deve-se ressaltar que, com o passar do tempo, novos receptores são sintetizados, tornando o fruto novamente sensível ao etileno, recuperando o processo de amadurecimento (BRON et al., 2006). O mesmo mecanismo de inibição não acontece em frutos mantidos em $\mathrm{AC}$ com absorção de $\mathrm{C}_{2} \mathrm{H}_{4}$, no qual o etileno foi removido somente durante o período de armazenamento, não havendo nenhum controle durante a comercialização.

Frutos mantidos em AC e frutos mantidos em AR associado à aplicação de 1-MCP (AR 1-MCP) durante dois meses também apresentaram FP similar no momento da saída da câmara fria e, novamente, os frutos que receberam 1-MCP foram os que mantiveram maior FP aos seis e 12 dias em TA. Após quatro meses de armazenamento, verificou-se uma leve redução na perda de FP nos frutos mantidos em AC, no entanto sem diferir dos frutos mantidos em AR 1-MCP (Tabela 1). Esse resultado é interessante, pois demonstra que, para a cultivar Tewi, o armazenamento em AR associado ao uso do 1-MCP tem efeito similar ao armazenamento em $A C$, na manutenção da FP, até dois meses.

Kiwis não tratados com 1-MCP e armazenados em AR foram os que apresentaram a menor FP, sendo essa redução verificada imediatamente à saída da câmara refrigerada, após dois meses de armazenamento. Após quatro meses, a redução na FP foi mais intensa, não podendo ser medida aos 12 dias devido ao avançado estádio de amadurecimento dos frutos (Tabela 1). A baixa FP observada nos frutos mantidos em AR está diretamente associada à presença de etileno, nessa condição, na qual nenhum fator, além do frio, foi empregado para o controle do etileno. A baixa eficiência da condição AR na manutenção da FP tem sido descrita para outras cultivares de kiwi (VIEIRA et al., 2010) e, inclusive, para outras espécies de frutos, como maçãs e peras (GWANPUA et al., 2014; Ll et al., 2013).

Considerando-se que firmeza de polpa abaixo de 14 a 18 N determina o fim do período de conservação (BARBONI et al., 2010), verifica-se que kiwis 'Tewi' podem permanecer armazenados durante dois meses em condições de AR 1-MCP, AC, AC 1-MCP e AC com absorção de $\mathrm{C}_{2} \mathrm{H}_{4}$, e durante quatro meses, em condições de $\mathrm{AC}$ 1-MCP e $\mathrm{AC}$ com absorção de $\mathrm{C}_{2} \mathrm{H}_{4}$, garantindo que o fruto chegue ao consumidor com firmeza média de $7 \mathrm{~N}$, quando mantidos durante, no máximo, seis dias em TA, após a retirada dos frutos da câmara fria.

Kiwis 'Tewi' mantidos em TA durante 12 dias após a colheita, sem nenhuma forma de conservação, apresentaram redução da FP e aumento do conteúdo de SS. No entanto, após o armazenamento, o aumento de SS nem sempre acompanhou a redução de FP (Tabelas 1 e 2). A perda de FP está diretamente associada à degradação do amido em sólidos solúveis, à degradação da parede celular e ao decréscimo no turgor celular. Trabalhos com outros frutos demonstraram que a queda do turgor celular, resultante do aumento de solutos no apoplasto, está diretamente relacionada à perda de firmeza de polpa (TONG et al., 1999; VICENTE et al., 2007). Porém, sabe-se que a conversão do amido em açúcares é o principal evento relacionado ao rápido amolecimento de kiwis nos estágios iniciais de redução da firmeza (ARPAIA et al., 1987). É conhecido

Tabela 2. Teor de sólidos solúveis de kiwis da cultivar Tewi, tratados e não tratados com 1-MCP, mantidos em diferentes condições de armazenamento, durante 2 e 4 meses. As avaliações foram realizadas no momento da saída da câmara fria (zero dia), e após 6 e 12 dias em temperatura ambiente.

\begin{tabular}{|c|c|c|c|c|c|c|}
\hline \multicolumn{7}{|c|}{ Teor de sólidos solúveis ( ${ }^{\circ}$ Brix) } \\
\hline \multirow{2}{*}{ TA } & \multicolumn{2}{|c|}{$0 \mathrm{dia}$} & \multicolumn{2}{|c|}{6 dias } & \multicolumn{2}{|c|}{12 dias } \\
\hline & \multicolumn{2}{|c|}{8,90} & \multicolumn{2}{|c|}{11,80} & \multicolumn{2}{|c|}{13,00} \\
\hline \multirow{2}{*}{ Armazenamento } & \multicolumn{3}{|c|}{2 meses } & \multicolumn{3}{|c|}{4 meses } \\
\hline & 0 dia & 6 dias & 12 dias & O dia & 6 dias & 12 dias \\
\hline AR & $13,33 \mathrm{bB}^{1 / \star} \alpha$ & $14,83 \mathrm{aA}^{\mathrm{ns}} \alpha$ & $15,20 \mathrm{aA} \alpha$ & $14,60 \mathrm{aB} \alpha$ & $15,27 \mathrm{bA \alpha}$ & nd \\
\hline AR MCP & $14,47 \mathrm{aB}^{\mathrm{ns}} \alpha$ & $14,57 \mathrm{aB}^{*} \alpha$ & $15,23 \mathrm{aA}^{\mathrm{ns}} \alpha$ & $14,67 \mathrm{aB} \alpha$ & $17,50 \mathrm{aA} \alpha$ & $15,40 \mathrm{aB} \alpha$ \\
\hline$A C$ & $12,40 \mathrm{cC}^{\star} \alpha$ & $13,03 b B^{\star} \alpha$ & $14,00 b^{\text {ns }} \alpha$ & $12,90 \mathrm{bcB} \alpha$ & $14,23 \mathrm{cA \alpha}$ & $14,33 \mathrm{bA \alpha}$ \\
\hline AC MCP & $13,50 \mathrm{bB}^{*} \alpha$ & $13,40 b B^{n s} \alpha$ & $14,10 \mathrm{bA}^{*} \alpha$ & $12,63 \mathrm{cB} \alpha$ & $13,33 \mathrm{cA} \alpha$ & $13,17 \mathrm{dA} \beta$ \\
\hline AC com absorção de $\mathrm{C}_{2} \mathrm{H}_{4}$ & $13,10 \mathrm{bB}^{\mathrm{ns}} \alpha$ & $13,47 \mathrm{bB}^{\star} \alpha$ & $14,28{b A^{*} \alpha}$ & $13,17 \mathrm{bB} \alpha$ & $14,27 \mathrm{bcA} \alpha$ & $13,87 \mathrm{cA \alpha}$ \\
\hline
\end{tabular}

1: Médias acompanhadas por mesma letra minúscula na coluna não diferem entre si pelo teste de Tukey $(p \leq 0,05)$, comparando-se as condições de armazenamentos dentro de cada dia para cada período de conservação. Médias acompanhadas por mesma letra maiúscula na linha não diferem entre si pelo teste de Tukey $(p \leq 0,05)$, comparando-se os dias dentro de cada condição de armazenamento para cada período de conservação. * $e^{\text {ns: }}$ Significativo e não significativo, respectivamente, pelo teste t $(p \leq 0,05)$, comparando-se os períodos de conservação dentro de cada condição de armazenamento para cada dia. $\alpha$ e $\beta$ : Significativo e não significativo, respectivamente, em relação à testemunha (temperatura ambiente-TA) pelo teste de Dunnett $(p \leq 0,05)$. nd: Não foi possível detectar. 
Atmosfera controlada associada ao 1-metilciclopropeno na preservação da qualidade de kiwi 'tewi'

Pegoraro, C. et al.

Tabela 3. Acidez titulável de kiwis da cultivar Tewi, tratados e não tratados com 1-MCP, mantidos em diferentes condições de armazenamento, durante 2 e 4 meses. As avaliações foram realizadas no momento da saída da câmara fria (zero dia), e após 6 e 12 dias em temperatura ambiente.

\begin{tabular}{|c|c|c|c|c|c|c|}
\hline \multicolumn{7}{|c|}{ Acidez titulável (\% de ácido cítrico) } \\
\hline \multirow{2}{*}{ TA } & \multicolumn{2}{|c|}{ O dia } & \multicolumn{2}{|c|}{6 dias } & \multicolumn{2}{|c|}{12 dias } \\
\hline & \multicolumn{2}{|c|}{2,22} & \multicolumn{2}{|c|}{1,86} & \multicolumn{2}{|c|}{1,55} \\
\hline \multirow{2}{*}{ Armazenamento } & \multicolumn{3}{|c|}{2 meses } & \multicolumn{3}{|c|}{4 meses } \\
\hline & $0 \mathrm{dia}$ & 6 dias & 12 dias & 0 dia & 6 dias & 12 dias \\
\hline AR & $1,64 \mathrm{CA}^{1 / \star} \alpha$ & $1,45 \mathrm{cB}^{*} \alpha$ & $1,35 \mathrm{cC} \alpha$ & $1,44 \mathrm{cA} \alpha$ & $1,19 \mathrm{cB} \alpha$ & nd \\
\hline AR MCP & $1,74 \mathrm{abA}^{*} \alpha$ & $1,70 \mathrm{aA}^{*} \alpha$ & $1,57 \mathrm{aB}^{\star} \beta$ & $1,64 \mathrm{aB} \alpha$ & 1,77 aA $\beta$ & $1,29 \mathrm{bC} \alpha$ \\
\hline$A C$ & $1,67 \mathrm{cA}^{*} \alpha$ & $1,41 \mathrm{CB}^{\text {ns }} \alpha$ & $1,41 \mathrm{bcB}^{\star} \alpha$ & $1,38 \mathrm{dA} \alpha$ & $1,41 \mathrm{bA \alpha}$ & $1,28 \mathrm{bA \alpha}$ \\
\hline AC MCP & $1,77 \mathrm{aA}^{*} \alpha$ & $1,64 \mathrm{aB}^{\star} \alpha$ & $1,59 \mathrm{aC}^{\star} \beta$ & $1,44 \mathrm{cA} \alpha$ & $1,47 \mathrm{bA \alpha}$ & $1,35 \mathrm{aB} \alpha$ \\
\hline AC com absorção de $\mathrm{C}_{2} \mathrm{H}_{4}$ & $1,70 \mathrm{bcA}^{*} \alpha$ & $1,53 \mathrm{bB}^{\star} \alpha$ & $1,45 b^{*} \alpha$ & $1,57 \mathrm{bA} \alpha$ & $1,40 \mathrm{bB} \alpha$ & $1,28 \mathrm{bC} \alpha$ \\
\hline
\end{tabular}

1\%: Médias acompanhadas por mesma letra minúscula na coluna não diferem entre si pelo teste de Tukey $(p \leq 0,05)$, comparando-se as condições de armazenamentos dentro de cada dia para cada período de conservação. Médias acompanhadas por mesma letra maiúscula na linha não diferem entre si pelo teste de Tukey $(p \leq 0,05)$, comparando-se os dias dentro de cada condição de armazenamento para cada período de

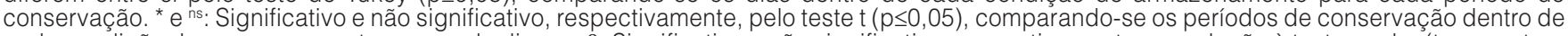
cada condiçã̃o de armazenamento para cada dia. $\alpha$ e $\beta$ : Significativo e não significativo, respectivamente, em relação à testemunha (temperatura ambiente-TA) pelo teste de Dunnett $(p \leq 0,05)$. nd: Não foi possível detectar.

que, durante o crescimento do fruto, kiwis acumulam grandes quantidades de amido, o qual é convertido em açúcares durante o estádio final de crescimento e no amadurecimento pós-colheita (FEMENIA et al., 2009).

Com relação ao teor de SS após o armazenamento, verificou-se que, após dois meses de conservação, o menor teor de sólidos solúveis foi verificado em frutos mantidos em $A C$, enquanto que frutos tratados com 1-MCP e mantidos em AR foram os que apresentaram maior teor de sólidos solúveis, em todos os períodos de avaliação (Tabela 2). Esses resultados diferem do estudo conduzido por Neves et al. (2003), que verificaram em kiwis 'Bruno', tratados com 1-MCP, menores teores de SS. A divergência quanto à atuação do 1-MCP nos teores de SS em frutos é notável e pode ser explicada pelo uso de diferentes cultivares e diferentes condições experimentais (BLANKENSHIP; DOLE, 2003). Após quatro meses de armazenamento, foi verificado maior conteúdo de sólidos solúveis em frutos mantidos em AR, independentemente do tratamento com 1-MCP (Tabela 2). Resultados parcialmente contrastantes foram encontrados por Brackmann et al. (2012), que, ao avaliarem kiwis 'Elmwood' armazenados durante cinco meses em AR, verificaram baixos níveis de SS e nenhuma diferença significativa entre frutos tratados e não tratados com 1-MCP. Esse comportamento diferencial, observado entre diferentes cultivares e diferentes condições de armazenamento, pode estar relacionado à conversão de açúcares para se manter o balanço de perda de carbono nos frutos, durante o armazenamento (FIDLER; NORTH, 1968).

Depois de dois meses de armazenamento, o maior conteúdo de acidez titulável foi verificado em frutos que receberam 1-MCP. Os frutos que permaneceram em AC com absorção de $\mathrm{C}_{2} \mathrm{H}_{4}$ apresentaram acidez titulável menor que frutos tratados com 1-MCP mantidos em AC. Após quatro meses de conservação, a acidez titulável teve comportamento similar (Tabela 3 ), sugerindo que a degradação dos ácidos orgânicos é influenciado pelo etileno. Resultados similares já haviam sido detectados em kiwis 'Bruno' (NEVES et al., 2003), em que a aplicação de 1-MCP reduziu a perda de acidez titulável. Esses resultados indicam que a utilização do 1-MCP ocasiona uma redução na velocidade de degradação dos ácidos orgânicos.

\section{Conclusão}

Kiwis 'Tewi' produzidos em condições edafoclimáticas da Serra Gaúcha apresentam bom potencial de conservação e podem ser armazenados durante dois meses em condições de armazenamento refrigerado e 1-metilciclopropeno (1-MCP), atmosfera controlada, atmosfera controlada e 1-MCP, e atmosfera controlada com absorção de $\mathrm{C}_{2} \mathrm{H}_{4}$, e, durante quatro meses, em condições de atmosfera controlada mais 1-MCP e atmosfera controlada com absorção de $\mathrm{C}_{2} \mathrm{H}_{4}$. $\mathrm{O}$ armazenamento refrigerado associado ao uso do 1-MCP apresentou efeito similar ao armazenamento em atmosfera controlada na manutenção da firmeza de polpa, sendo uma alternativa interessante para os produtores.

\section{Agradecimentos}

À empresa Silvestrin Frutas, pelo fornecimento do kiwi, e a CAPES e CNPq, pelo suporte financeiro.

\section{Referências}

ALVES, E. O.; STEFFENS, C. A.; AMARANTE, C. V. D. T.; HENDGES, M. V.; ZANARDI, O. D.; MIQUELOTO, A.; SILVEIRA, J. P. G.; BRACKMANN, A. Amadurecimento de kiwis 'bruno' 
Atmosfera controlada associada ao 1-metilciclopropeno na preservação da qualidade de kiwi 'tewi'

Pegoraro, C. et al.

submetidos ao dano mecânico de impacto e ao tratamento com 1-metilciclopropeno. Bragantia, Campinas, v. 69, n. 3, p. 753-758, 2010. http://dx.doi.org/10.1590/S000687052010000300029 .

ARPAIA, M. L.; LABAVITCH, J. M.; GREVE, C.; KADER, A. A. Changes in cell wall components of kiwifruit during storage in air or controlled atmospheres. Journal of the American Society for Horticultural Science, Alexandria, v. 112, n. 3, p. 474-481, 1987.

BARBONI, T.; CANNAC, M.; CHIARAMONTI, N. Effect of cold storage and ozone treatment on physicochemical parameters, soluble sugar and organic acids in Actinidia deliciosa. Food Chemistry, Philadelphia, v. 121, n. 4, p. 946-951, 2010. http:// dx.doi.org/10.1016/j.foodchem.2010.01.024.

BLANKENSHIP, S. M.; DOLE, J. M. 1-Methylcyclopropene: a review. Postharvest Biology and Technology, Amsterdam, v. 28 , n. 1, p. 1-25, 2003. http://dx.doi.org/10.1016/S09255214(02)00246-6.

BLUM, J.; AYUB, R. A. Controle do amadurecimento do kiwi Cv. Monty com 1-metilciclopropeno. Revista Brasileira de Fruticultura, Jaboticabal, v. 31, n. 1, p. 39-43, 2009.

BRACKMANN, A.; ARRIEL, A.; OSTER, A. H. Armazenamento refrigerado de kiwi em atmosfera normal e controlada. Revista Brasileira de Agrociência, Pelotas, v. 1, n. 2, p. 107-111, 1995.

BRACKMANN, A.; WEBER, A.; BOTH, V.; SANTOS, J. R. A.; ANESE, R. O. Armazenamento de kiwi cv. Elmwood em atmosfera controlada e manejo do etileno. Revista de Ciências Agroveterinárias, Lages, v. 11, n. 2, p. 99-105, 2012.

BRON, I. U.; JACOMINO, A. P.; PINHEIRO, A. L. Influence of ripening stage on physical and chemical attributes of 'Golden' papaya fruit treated with 1-Methylcyclopropene. Bragantia, Campinas, v. 65 , n. 4, p. 553-558, 2006. http://dx.doi. org/10.1590/S0006-87052006000400003.

FEMENIA, A.; SASTRE-SERRANO, G.; SIMAL, S.; GARAU, M. C.; EIM, V. S.; ROSSELLÓ, C. Effects of air-drying temperature on the cell walls of kiwifruit processed at different stages of ripening. LWT - Food Science and Technology, Estados Unidos, v. 42, p. 106-112, 2009.

FERGUSON, A. R. New temperate fruits: Actinidia chinensis and Actinidia deliciosa. In: JANICK, J. (Ed). Perspectives on new crops and new uses. Alexandria: ASHS Press, 1999. p. 342-347.

FIDLER, L. C.; NORTH, C. J. The effect of conditions of storage on the respiration of apples: IV. Changes in concentration of possible substrates of respiration, as related to production of carbon dioxide and uptake of oxygen by apples at low temperatures. Journal of Horticultural Science, London, $n$. 43, p. 429-439, 1968.

GWANPUA, S. G.; VAN BUGGENHOUT, S.; VERLINDEN, B. E.; CHRISTIAENS, S.; SHPIGELMAN, A.; VICENT, V.; KERMANI, Z. J.; NICOLAI, B. M.; HENDRICKX, M.; GEERAERD, A. Pectin modifications and the role of pectin-degrading enzymes during postharvest softening of Jonagold apples. Food Chemistry, Philadelphia, v. 158, p. 283-291, 2014. http://dx.doi. org/10.1016/j.foodchem.2014.02.138. PMid:24731343.

HU, Q.; FANG, Y.; YANG, Y.; MA, N.; ZHAO, L. Effect of nanocomposite-based packaging on postharvest quality of ethylene-treated kiwifruit (Actinidia deliciosa) during cold storage. Food Research International, Amsterdam, v. 44, n. 6, p. 1589-1596, 2011. http://dx.doi.org/10.1016/j. foodres.2011.04.018.

ILINA, N.; ALEM, H. J.; PAGANO, E. A.; SOZZI, G. O. SOZZI, G. O. Suppression of ethylene perception after exposure to cooling conditions delays the progress of softening in 'Hayward' kiwifruit. Postharvest Biology and Technology, Amsterdam, v. 55, n. 3, p. 160-168, 2010. http://dx.doi.org/10.1016/j. postharvbio.2009.11.005.

KOUKOUNARAS, A.; SFAKIOTAKIS, E. Effect of 1-MCP pre-storage treatment on ethylene and $\mathrm{CO} 2$ production and quality of 'Hayward' kiwifruit during shelf-life after short, medium and long term cold storage. Postharvest Biology and Technology, Amsterdam, v. 46, n. 2, p. 174-180, 2007. http:// dx.doi.org/10.1016/j. postharvbio.2007.05.002.

LALLU, N.; BURDON, J. Experiences with recent postharvest technologies in kiwifruit. Acta Horticulturae, Brugg, v. 753, p. 733-740, 2007.

LI, F.; ZHANG, X.; SONG, B.; LI, J.; SHANG, Z.; GUAN, J. Combined effects of 1-MCP and MAP on the fruit quality of pear (Pyrus bretschneideri Reld Cv. Laiyang) during cold storage. Scientia Horticulturae, Amsterdam, v. 164, p. 544-551, 2013. http://dx.doi.org/10.1016/j.scienta.2013.10.018.

NEVES, L. C.; CORRENT, A.; MARINI, L.; LUCCHETTA, L.; ZANUZZO, M. R.; GONÇALVES, E. D.; ZANATTA, J.; CANTILLANO, F. R.; ROMBALDI, C. V. Atmosfera modificada e 1-metilciclopropeno na conservação pós-colheita de kiwis. Revista Brasileira de Fruticultura, Jaboticabal, v. 25, n. 3, p. 390-393, 2003.

PIRIYAVINIT, P.; KETSA, S.; VAN DOORN, W. G. 1-MCP extends the storage and shelf life of mangosteen (Garcinia mangostana L.) fruit. Postharvest Biology and Technology, Amsterdam, v. 6, n. 1, p. 15-20, 2011. http://dx.doi.org/10.1016/j. postharvbio.2011.02.007.

SAS Institute. SAS system for Windows, version 9.1. Cary: SAS Institute, 2002

SILVEIRA, S. V.; ANZANELLO, R.; SIMONETTO, P. R.; GAVA, R.; GARRIDO, L. R.; SANTOS, R. S. S.; GIRARDI, C. L. Aspectos técnicos da produção de kiwi. Bento Gonçalves: Empresa Brasileira de Pesquisa Agropecuária, 2012. Documentos, 79. Disponível em: <http://www.cnpuv.embrapa.br/publica/ documentos/doc079.pdf>. Acesso em: 17 ago. 2015.

TONG, C.; KRUEGER, D.; VICKERS, Z.; BEDFORD, D.; LUBY, J.; EL-SHIEKH, A.; SHACKEL, K.; AHMADI, H. Comparison 
Atmosfera controlada associada ao 1-metilciclopropeno na preservação da qualidade de kiwi 'tewi'

Pegoraro, C. et al.

of softening-related changes during storage of "Honeycrisp" apple, its parents, and "Delicious". Journal of the American Society for Horticultural Science, Alexandria, v. 124, n. 4, p. 407-415, 1999.

VICENTE, A. R.; SALADIÉ, M.; ROSE, J. K.; LABAVITCH, J. M. The linkage between cell wall metabolism and fruit softening: looking to the future. Journal of the Science of Food and Agriculture, Londres, v. 87, n. 8, p. 1435-1448, 2007. http:// dx.doi.org/10.1002/jsfa.2837.

VIEIRA, M. J.; ARGENTA, L. C.; AMARANTE, C. V. T.; STEFFENS, C. A.; VIEIRA, A. M. F. D. Preservação da qualidade pós-colheita de kiwi 'Bruno' pelo controle do etileno. Revista Brasileira de Fruticultura, Jaboticabal, v. 32, n. 2, p. 397-406, 2010.
WATKINS, C. B. The use of 1-methylcyclopropene (1-MCP) on fruits and vegetables. Biotechnology Advances, Oxford, v. 24, n. 4, p. 389-409, 2006. http://dx.doi.org/10.1016/j. biotechadv.2006.01.005. PMid:16530376.

YANG, Q.; ZHANG, Z.; RAO, J.; WANG, Y.; SUN, Z.; MA, Q.; DONG, $X$. Low-temperature conditioning induces chilling tolerance in 'Hayward' kiwifruit by enhancing antioxidant enzyme activity and regulating en-dogenous hormones levels. Journal of the Science of Food and Agriculture, Nova lorque, v. 93, n. 15, p. 3691-3699, 2013.

ZOLFAGHARI, M.; SAHARI, M. A.; SAMADLAY, H. Physicochemical and enzymatic properties of five kiwi fruit cultivars during cold storage. Food and Bioprocess Technology, Nova lorque, v. 3, n. 2, p. 239-264, 2010. 